\title{
The promises and challenges of health information technology in primary health care
}

Health information technology holds promise to solve challenges in primary health care related to workforce shortages, quality improvement and increasing patient engagement in their care. Clinical health technology, such as electronic health records, may augment primary care provider capabilities so that they may be able to do more with less, therefore providing better care to increasing numbers of patients with greater clinical complexity. Consumer health technologies may help provide providers with better information about their patients' needs and behaviors outside of the clinic. These technologies also hold the promise of allowing patients to better manage their own health and wellness at home, so that they can better adhere to care plans. The promise of technology to improve primary care is great and attainable, but additional research is needed to make these goals a reality. Challenges to achieving these goals include a deficient of basic research about primary care work, care provider needs and patient capabilities and limitations. This basic science is needed to design technologies that can be integrated in primary care work systems and patient lives. Without human and system centered designs technologies can add additional complexity, frustration and diminish trust between patients and providers. Additional research is also needed to better understand the successes and failures of technology in primary care environments.

Primary care is the first point of care for most patients and is characterized by a long-term relationship between a patient and their care provider. The Institute of Medicine defines primary care as 'the provision of integrated, accessible health care services by clinicians who are accountable for addressing a large majority of personal health care needs, developing a sustained partnership with patients, and practicing in the context of family and community' (p. 15) (Donaldson et al., 1994; 1996). By definition primary care providers are responsible for many health care system goals such as providing health education, disease prevention, continuity of care, integrated care, health promotion, in addition to diagnosis and treatment.

(C) Cambridge University Press 2014
Primary care providers are trained to provide comprehensive, first contact and continuing care for persons with any undiagnosed illness, symptom, or health concern. Primary care physicians are often the first to identify and diagnosis major chronic diseases and illnesses such as cancer, diabetes, heart disease, hypertension, and depression. In addition to diagnosis, much of the care for chronic illnesses has shifted to primary care settings. Eight-seven percent of Americans aged 65-79 live with at least one chronic condition and the place of care for this population has largely shifted to primary care settings; this shift is expected to increase - adding additional strain to the primary care system. More generally, 57 million people in the United States lived with multiple chronic conditions in 2000 and this number is expected to increase to 81 million by 2020 (Wolff et al., 2002). Primary care will likely be the place of care for these patients for diagnosis, treatment, and recovery of their conditions. Technology may be able to augment primary care provider capabilities and use of such technologies may be one defining feature of future primary health care provision (Bryar et al., 2012) to better engage patients in their care as the number of patients grow and their health needs increase in complexity.

Primary care is a national and global concern, the World Health Organization advocates for a comprehensive primary health care system as primary health care results in better health outcomes, reduced health disparities and lower costs, including reduced spending on avoidable emergency room visits and hospital care (WHO, 2008). One barrier to achieving this goal is the growing deficit of primary care providers in the United States and throughout the world. There are increasingly more patients who have access to care, coupled with a growing population of patients that have complex health care needs (eg, older, more chronic disease, increased comorbidities), which is exponentially exceeding the supply of qualified primary care providers (Petterson et al., 2012). Additionally, fewer physicians in the United States are choosing to work in primary care environments, and many 
physicians are leaving the primary care workforce, which contributes to a growing deficient. With fewer physicians practicing, there are also fewer opportunities for training and mentoring new physicians.

The Maslach Burnout Inventory was used to study burnout and satisfaction among US physicians, results show that $38 \%$ of physicians surveyed reported high emotional exhaustion, $29 \%$ had high depersonalization, and $12 \%$ had a low sense of personal accomplishment, with primary care physicians (internal medicine and family medicine) having the highest amounts of burnout (Shanafelt et al., 2012). This rate of burnout is disproportionately higher for women (McMurray et al., 2000) and physicians who provide care in minority serving clinics (Varkey et al., 2009). Lower pay, high workloads, long hours, and a sense of being undervalued may be influencing primary care physicians to leave the field prematurely while simultaneously preventing young physicians from entering the profession (NEHI, 2009). The proportion of primary care physicians in the United States has decreased from $50 \%$ of all physicians in 1950 to just over 30\% in 2007 (NEHI, 2009). While technologies such as electronic health records were designed to improve physician work life and mitigate some aspects of burnout, recent studies are showing that electronic health records may significantly worsen professional satisfaction for primary care physicians (Babbott et al., 2013; Friedberg et al., 2013). The factors listed as contributors to low satisfaction with electronic health records are largely related to electronic health record (EHR) usability and poor integration into care.

\section{EHR systems}

EHRs are able to integrate patients' retrospective, concurrent, and prospective health information and are easily accessible to different caregivers as well as public health agencies and research organizations. Compared with paper-based health records, EHRs improve quality, efficiency and continuity of health care by facilitating coordinated approaches among different caregivers and enabling tracking of people's health information and care activities. A survey involving clinicians and administrative staff reported increased efficiency in retrieving medical records, storing patient information, coordination of care, and office operations (Goetz Goldberg et al., 2012). Another study of 16352 nurses working in 316 hospitals in four states suggested that the implementation of a basic EHR may result in improved and more efficient nursing care, better care coordination, and patient safety (Kutney-Lee and Kelly, 2011). EHRs can also provide timely updated data for public health surveillance and research to inform public health practice and health policy planning, which benefits the health of more people with lower costs (Hayrinen et al., 2008).

Widespread implementation and usage of EHRs and other health information technologies may improve the quality and efficiency of health care in the United States (Chaudhry et al., 2006; Fang et al., 2011). Barriers to implementing EHRs include costs, the need for training, and the culture change required to embrace technology (Cherry and Ali, 2008). The American Recovery and Reinvestment Act provided a $\$ 19$ billion fund to promote the adoption of EHRs with the requirement of 'meaningful use'. This requirement states that EHRs should be used effectively and provide quality and efficiency in the health care system (Blumenthal, 2009). Despite this goal, a National Research Council (NRC) report indicates that current EHR technologies are poorly designed; and more specifically the technology does not compliment care providers cognitive capabilities and needs (Stead and Lin, 2009). Furthermore, the NRC report states that current EHRs are not designed with human-computer interaction and human factors and ergonomics design principles, which contributes to inefficient use (Stead and Lin, 2009). One reason for poorly designed technologies is that there is very little basic research about the science of how primary care providers work. Future studies should continue to explore how primary care providers work and think to better develop guidelines for technologies that are safe, easy to use, efficient, and effective.

\section{Consumer health technologies}

Primary care is the de facto location for most patient care and prevention; it is also an ideal site for the integration of patient-facing or consumer health technologies. These tools range from 
mobile technologies to help patients manage their specific symptoms to patient portals that allow patients to keep track of the care they receive through a personal health record. Two challenges exist with incorporating consumer health technologies into primary care, first is that long-term adoption is generally low for mobile health technologies and other applications that patients can find in the consumer market (Montague, 2012). For many of these applications, patients may download and try for a short amount of time, but utilization declines after a week. This low adoption may be related to poor usability, where tools are not designed with patients' needs in mind, or usefulness, where the tools are simply not effective at managing health or helping with behavior changes. More research is needed to determine which technologies will be useful for patients and how to design usable technologies that can be integrated into patients' lives.

Adoption of personal health records is rising, but there is a growing digital divide where unrepresented minorities and traditional underserved patients lag in adoption and utilization (Yamin et al., 2011). The second challenge with consumer health technologies is that while patients may benefit from using technology to manage their medication regimens or change health behaviors, these technologies are not regularly incorporated into the primary care system. Care providers often do not have access to the data that patients are collecting about themselves and are therefore unable to provide clinical oversight and feedback that may help the patient or recognize errors. Integrating data from patients into clinical encounters requires a better understanding of primary care work and clinician information needs as well as innovation in clinical informatics. Designing tools that patients find both useful and usable requires a better understanding of patients' needs and lives outside of the health care system.

Technology is capable of transforming primary care and thus solving some of the growing challenges that limit its current reach. Technology may allow care providers to be more efficient and effective, and improve providers' quality of life. Technology may also be able to improve patient physician relationships, by better engaging patients in their care through new and innovative tools. However, in order for these changes to become a reality additional work is needed to better understand primary care, and a better understanding of how to translate primary care needs into usable and useful technologies for patients and providers.

\section{Enid Montague \\ Editorial Board Member PHCR\&D, General Internal Medicine and Geriatrics, Industrial Engineering and Management Systems, Northwestern University, IL, USA}

\section{References}

Babbott, S., Manwell, L., Brown, R., Montague, E., Williams, E., Schwartz, M., Hess, E. and Linzer, M. 2013: Electronic medical records and physician stress in primary care: results from the MEMO Study. Journal of the American Medical Informatics Association: JAMIA, e100-e106.

Blumenthal, D. 2009: Stimulating the adoption of health information technology. New England Journal of Medicine 360, 1477.

Bryar, R., Kendall, S. and Mogotlane, S. 2012: Reforming primary health care: a nursing perspective. Geneva: International Centre for Human Resources in Nursing, ICN.

Chaudhry, B., Wang, J., Wu, S., Maglione, M., Mojica, W., Roth, E., Morton, S.C. and Shekelle, P.G. 2006: Systematic review: impact of health information technology on quality, efficiency, and costs of medical care. Annals of Internal Medicine 144, 742.

Cherry, R.A. and Ali, J. 2008: Current concepts in simulationbased trauma education. Journal of Trauma 65, 1186-93.

Donaldson, M.S., Yordy, K.D., Lohr, K.N. and Vanselow, N.A. 1996: Primary care: America's health in a new era. Washington, DC: National Academies Press.

Donaldson, M.S., Yordy, K.D. and Vanselow, N.A. 1994: Defining primary care: an interim report. Washington, DC: Institute of Medicine.

Fang, H., Peifer, K., Chen, J. and Rizzo, J. 2011: Health information technology and physicians' perceptions of healthcare quality. The American Journal of Managed Care 17, e66-e70.

Friedberg, M.W., Chen, P.G., Busum, K.R.V., Aunon, F.M., Pham, C., Caloyeras, J.P., Mattke, S., Pitchforth, E., Quigley, D.D., Brook, R.H., Crosson, F.J. and Tutty, M. 2013: Factors Affecting Physician Professional Satisfaction and Their Implications for Patient Care, Health Systems, and Health Policy, Rand Corporation.

Goetz Goldberg, D., Kuzel, A.J., Feng, L.B., DeShazo, J.P. and Love, L.E. 2012: EHRs in primary care practices: benefits, challenges, and successful strategies. The American Journal of Managed Care 18, e48-e54.

Hayrinen, K., Saranto, K. and Nykanen, P. 2008: Definition, structure, content, use and impacts of electronic health 
records: a review of the research literature. International Journal of Medical Informatics 77, 291-304.

Kutney-Lee, A. and Kelly, D. 2011: The effect of hospital electronic health record adoption on nurse-assessed quality of care and patient safety. Journal of Nursing Administration 41, 466-72.

McMurray, J.E., Linzer, M., Konrad, T.R., Douglas, J., Shugerman, R. and Nelson, K. 2000: The work lives of women physicians results from the physician work life study. The SGIM Career Satisfaction Study Group. Journal of General Internal Medicine 15, 372-80.

Montague, E. 2012: Improving consumer health IT application development: lessons from other industries, findings from key informant interviews. Rockville, MD: Agency for Healthcare Research and Quality.

NEHI. 2009: Remaking primary care: from crisis to opportunity. Cambridge, MA: New England Health Care Institute.

Petterson, S.M., Liaw, W.R., Phillips, R.L. Jr., Rabin, D.L., Meyers, D.S. and Bazemore, A.W. 2012: Projecting US primary care physician workforce needs: 2010-2025. Annals of Family Medicine 10, 503-509.

Shanafelt, T.D., Boone, S., Tan, L., Dyrbye, L.N., Sotile, W., Satele, D., West, C.P., Sloan, J. and Oreskovich, M.R.
2012: Burnout and satisfaction with work-life balance among us physicians relative to the general us population. Archives of Internal Medicine 172, 1377-85.

Stead, W.W. and Lin, H. 2009: Computational technology for effective health care: immediate steps and strategic directions. Washington, DC: National Academies Press 243-50.

Varkey, A.B., Manwell, L.B., Williams, E.S., Ibrahim, S.A., Brown, R.L., Bobula, J.A., Horner-Ibler, B.A., Schwartz, M.D., Konrad, T.R. and Wiltshire, J.C. 2009: Separate and unequal: clinics where minority and nonminority patients receive primary care. Archives of Internal Medicine 169, 243.

WHO. 2008: The world health report 2008: primary health care: now more than ever. Geneva: World Health Organization.

Wolff, J.L., Starfield, B. and Anderson, G. 2002: Prevalence, expenditures, and complications of multiple chronic conditions in the elderly. Archives of Internal Medicine 162, 2269-76.

Yamin, C.K., Emani, S., Williams, D.H., Lipsitz, S.R., Karson, A.S., Wald, J.S. and Bates, D.W. 2011: The digital divide in adoption and use of a personal health record. Archives of Internal Medicine 171, 568-74. 